ojs.uv.es/index.php/qfilologia/index

Rebut: I6.06.2020. Acceptat: 23.08.2020

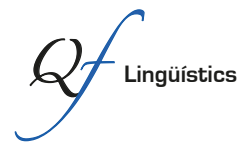

Per a citar aquest article: Madail Gafanha, Raquel. 2020. "O ato ilocutório de queixa na pragmática da interlíngua: estudo de caso”. Quaderns de Filologia: Estudis Lingüístics XXV: I5I-I68.

doi: $10.7203 /$ Q.25.19077

\title{
0 ato ilocutório de queixa na pragmática da interlíngua: estudo de caso
}

\section{The illocutionary act of complaint in interlanguage pragmatics: a case study}

\author{
Raquel Madail Gafanha \\ Faculdade de Letras, Universidade de Coimbra \\ mraquelmgafanha@gmail.com
}

Resumo: Analisa-se o ato ilocutório de queixa em aprendentes de Português Língua Estrangeira (PLE) de língua materna espanhola em três níveis de proficiência linguística. Descreve-se o ato de queixa (i) identificando a informação semântica (Murphy \& Neu, I996); (ii) traçando tendências de realização em relação ao grau de ameaça à face (Olshtain \& Weinbach, I993); e (iii) assinalando os principais mecanismos linguísticos. Os dados permitem algumas conclusões: (i) contexto formal e informal apresentam diferentes fórmulas semânticas; (ii) 'distância social' e 'poder' condicionam as escolhas linguísticas; (iii) primazia das estratégias de cortesia em contexto formal e ausência em contexto informal.

Palavras chave: pragmática; interlíngua; atos ilocutórios; queixa; português língua estrangeira (ple).

Abstract: The current paper presents a study that analyzes the illocutionary act of complaint performed by Spanish speakers of Portuguese as a Foreign Language (PLE). It describes the act of complaint by (i) identifying its semantic information (Murphy \& Neu, I996); (ii) tracing realization trends regarding the degree of face-threat (Olshtain \& Weinbach, I993); and (iii) pointing out the main linguistic mechanisms used. Data analysis allows us to draw some conclusions, namely: (i) formal and informal contexts present different semantic formulas; (ii) language choices are highly conditioned by the variables 'social distance' and 'power'; (iii) courtesy strategies are mostly used in formal contexts and may even be absent in informal contexts. Keywords: pragmatics; interlanguage; illocutionary acts; complaint; portuguese foreign language (ple). 


\section{Introdução}

A investigação dos atos ilocutórios em PLNM (português língua não materna) tem revelado alguma produtividade nos últimos anos em Portugal e, por esse motivo, acreditamos que este estudo contribui para a compreensão do domínio da competência comunicativa na interlíngua em português.

Constitui objetivo deste estudo descrever os atos de queixa a partir da identificação da informação semântica presente no ato ilocutório, de acordo com a estrutura interna proposta por Murphy \& Neu (I996) e da identificação de tendências de realização em relação ao grau de face-threat nos termos propostos por Olshtain \& Weinbach (I993). É também nosso objetivo assinalar os principais mecanismos linguísticos usados na produção do ato ilocutório em apreço.

Ao delinear o quadro teórico que sustenta a nossa análise, apontamos as principais características do ato de queixa para, em seguida, expor e discutir a informação proporcionada pela análise do corpus oral composto por informantes hispanofalantes.

\section{Enquadramento teórico}

Não são muitos os estudiosos que se têm debruçado sobre a pragmática, e em particular, sobre atos ilocutórios no âmbito da interlíngua do português. Se é certo que encontramos literatura sobre alguns atos ilocutórios, como o pedido ou a desculpa, também é certo que existem outros que praticamente não foram abordados ainda. É o caso da queixa, ato ilocutório que, comparativamente com aqueles, tem sido pouco estudado e, tanto quanto nos é dado a conhecer, ainda não foi tratado para o português, nem em PLM nem em PLNM ${ }^{\mathrm{I}}$.

No que respeita à análise da queixa na interlíngua ${ }^{2}$, alguns estudos demonstram o avanço do conhecimento neste âmbito em relação a várias línguas. Destacamos Boxer (I993, I996) no âmbito da queixa indireta, enquanto que Murphy \& Neu (I996) realizam uma abordagem semântica. Por outro

\footnotetext{
${ }^{\mathrm{I}}$ Há a registar a tese de doutoramento de Macêdo (I999) sobre reclamação e pedido de desculpas.

${ }^{2}$ Convocamos o conceito de 'interlíngua' como o sistema linguístico do falante não nativo e que não corresponde ao sistema linguístico do falante nativo. Blum-Kulka \& Olshtain (I986), por exemplo, demonstram que os atos de discurso com os valores ilocutórios de desculpa e de pedido são atualizados distintamente por falantes não nativos e falantes nativos.
} 
lado, Olshtain \& Weinbach (I993) analisam a queixa numa perspetiva de ameaça da face e Trosborg (I995) realiza uma investigação nos diferentes níveis linguísticos, entre outros estudos mais pontuais. É, portanto, destes investigadores que recolhemos o suporte teórico para este estudo.

Ora, se em contexto de língua materna este ato de discurso com valor ilocutório de queixa pode implicar problemas de ameaça da face, em falantes não nativos esta situação é ainda mais relevante, na medida em que a falta de adequação ao contexto comunicacional dos mecanismos linguísticos que correspondem à intenção comunicativa do falante pode ser entendida como sinónimo de descortesia, falta de respeito, de cuidado ou de credibilidade, e, nesse sentido, geradora de conflitos (Barron, 2003 citado por Sabaté I Dalmau, 2009: 142; Murphy \& Neu, I996)³.

Por conseguinte, é de suma importância que os falantes de uma língua estrangeira sejam competentes pragmaticamente, isto é, que saibam adaptar as suas escolhas linguísticas ao contexto e à intenção comunicativa.

\subsection{Teoria dos Atos de Fala}

Nos termos propostos por Searle (1976), o ato de queixa é um ato expressivo, na medida em que o falante expressa os seus sentimentos, manifestando o seu descontentamento em relação à situação descrita na proposição ${ }^{4}$ (ofensa). Não obstante, e atendendo à mesma taxonomia, também será pertinente considerar, concomitantemente, a queixa como um ato diretivo, na medida em que o falante pode direcionar o ouvinte para remediar a ofensa ou evitar a sua repetição, seja através de uma ordem, de um pedido ou mesmo de uma ameaça.

Em sintonia com a existência de diferentes forças ilocutórias, Murphy \& $\mathrm{Neu}$ (I996: 2I4) utilizam a designação speech act set (conjunto de atos de fala) em detrimento de speech act (ato de fala). Parece-nos pertinente esta abordagem, e será esta a por nós adoptada, uma vez que o ato de queixa nem sempre se realiza unicamente através de um enunciado, mas por meio de um

\footnotetext{
3 Também Boxer (I996: 218) realça esta ideia: “Native speakers, however, typically interpret sociolinguistics errors as rudeness rather than as the transfer of different sociolinguistic rules". 4 Por simplificação terminológica, entendemos neste estudo considerar o termo geral ofensa para todas as situações que possam originar um ato de queixa, queixoso para o falante e visado para o interlocutor que praticou a ofensa.
} 
conjunto de frases ${ }^{5}$ que pode inclusivamente entrar no nível dialógico. Não será despiciendo, pois, afirmar que diferentes forças ilocutórias computam para a realização do ato de queixa, corroborando a ideia de que se trata de um complexo ilocutório.

\subsection{Teoria da Cortesia}

Trosborg (I995: 132) assere que os atos de queixa "are by their very nature designed to cause offence and they are therefore highly threatening to the social relationship between speaker and hearer". Decorre, naturalmente, desta afirmação que a queixa é um face-threatening act (FTA) nos termos desenvolvidos por Brown \& Levinson (I999).

A queixa constitui uma ameaça da face positiva do visado porque atinge a sua imagem pública, a necessidade de aceitação da sua imagem pelos outros, mas também pode ser simultaneamente uma ameaça da face negativa por implicar um pedido de compensação por parte do visado, logo uma invasão da sua privacidade, liberdade.

Paralelamente, a queixa é também uma ameaça das faces positiva e negativa do queixoso. Da face positiva na medida em que a concretização da queixa implica uma assunção das suas fragilidades e fraquezas decorrentes da ofensa praticada pelo outro, e da face negativa uma vez que o queixoso tem necessidade de reclamar a sua liberdade de ação que foi afetada pela ofensa.

De modo a equilibrar a vulnerável relação comunicativa entre queixoso e visado, existe necessidade de neutralizar, mitigar o FTA, sendo, pois, identificável uma correlação entre o grau de ameaça da face e o grau de indireção com que a queixa é realizada. Quanto mais direta e explícita é a queixa, menor é o recurso a elementos de cortesia e a ameaça da face é concretizada bald-on-record. Tratando-se de uma queixa explícita mas cordial, o queixoso recorre a estratégias de cortesia positiva e negativa ${ }^{6}$ na produção do FTA, ou seja, a ameaça da face é on-record. Quanto mais indireta e implícita for a queixa, menor será o grau de ameaça da face e maior o grau de delicadeza (recurso a metáforas, ironias, perguntas retóricas...), podendo mesmo a queixa ser concretizada de modo indireto, ou seja, off-record.

\footnotetext{
${ }_{5}$ Idêntica posição assumem Geluykens \& Kraft (2003: 252) e Beltrán Palanques (20I6: I03-IO4). ${ }^{6}$ Recorremos a Leech (I983: 83-84) para caracterizar as estratégias de cortesia negativa como aquelas que permitem minimizar "the impoliteness of impolite illocutions" e as de cortesia positiva como as que maximizam "the politeness of polite illocutions".
} 
A queixa, enquanto ato naturalmente conflituoso, é por definição não cortês. Leech (1983: I05) considera que é impossível haver cortesia no ato de queixa já que "to threaten or curse someone in a polite manner is virtually a contradiction in terms". Porém, todos reconhecemos a importância de recorrer a estratégias de cortesia num ato desta natureza, de modo a evitar quebras comunicacionais ou novos conflitos. Trosborg (1995: 313) destaca que o uso de modalizadores permite alcançar diferentes graus de cortesia mantendo o mesmo tipo de direção.

Brown \& Levinson (I999) referem que existem três variáveis primordiais que concorrem para o grau de delicadeza do ato realizado e influenciam o agravamento / a atenuação de um FTA, ou seja, que interferem na escolha dos mecanismos linguísticos. São elas a distância social (D), o poder (P) e as convenções socioculturais (R). De facto, o modo como a queixa é concretizada entre pares é bastante diferente de uma realizada entre pessoas onde há relações de poder evidentes, bem como se é concretizada num local público ou num privado. As consequências da realização do FTA são, por isso, potencialmente condicionadas pelas escolhas linguísticas do queixoso.

\subsection{Caracterização do ato ilocutório de queixa}

O ato ilocutório de queixa é o ato através do qual o falante expressa lamentação ou ressentimento, protesta ou reclama, manifestando, assim, o seu desagrado em relação à situação exposta. Na queixa, a situação descrita na proposição situa-se sempre no passado. Ou seja, existe um conjunto de pré-condições para a realização do ato ilocutório de queixa. Olshtain \& Weinbach (I993) apontam 4: (i) o ouvinte realiza um ato socialmente não aceite (socially unacceptable act - SUA), contrário às normas sociais partilhadas pelo falante e pelo ouvinte, ou , ainda que não o sendo, é contrário às expectativas pessoais; (ii) o falante entende o SUA como uma ação com consequências desfavoráveis para si e/ ou para a generalidade das pessoas; (iii) o discurso do falante é posterior ao SUA e relaciona-se com ele direta ou indiretamente, daí a força ilocutória de censura; e (iv) o falante entende o SUA como libertador de um entendimento implícito numa relação de cooperação com o ouvinte e, nesse sentido, legitimador do direito de pedir remediação.

Para a caracterização da queixa, assumimos desde o início que existem dois tipos de queixa: a direta e a indireta. A queixa direta envolve acusação explícita ou implícita e/ou pedido de remediação. Trata-se de um ato que pela 
sua natureza cria tensão entre os interlocutores, e, por esse motivo, é potencialmente conflituoso, podendo inclusivamente provocar brechas comunicacionais (Leech, I983). Já na queixa indireta, não existe qualquer acusação com o objetivo de remediação da ofensa, mas sim a simples manifestação de desagrado e o interlocutor pode não ser o visado, mas sim um terceiro (por exemplo, numa cantina, um falante dirige-se ao seu interlocutor, que não é o responsável pela ofensa, dizendo 'A comida hoje não está muito boa!'). Boxer (I996: 232) caracteriza funcionalmente este tipo de queixa como conversationel openers, ou seja, a queixa indireta utilizada como elemento introdutor conversacional para criar empatia com pessoas com muito pouca ou nenhuma intimidade social. Neste sentido, não é plausível considerar a queixa indireta como um típico FTA (Ghaznavi, 20I7). Neste estudo, ocupar-nos-emos apenas da queixa direta.

\subsection{Tipologiais do ato ilocutório de queixa}

Existem diferentes propostas de classificação do ato ilocutório de queixa, que podemos encontrar descritas em Toledo Azócar (20I6). Apresentamos apenas as propostas que pautam a nossa investigação.

Entre os estudos de língua estrangeira que se têm debruçado sobre a queixa, a proposta que tem recebido mais aceitação entre pares é a categorização de Olshtain \& Weinbach (I993). Estes linguistas propõem uma taxonomia do ato da queixa dividida em 5 níveis, em função do grau de ameaça da face do ato de queixa em relação ao visado. O primeiro nível (I) é Below the level of reproach, em que o queixoso não faz referência explícita à ofensa, deixando espaço para que o visado considere se existe ou não queixa. O segundo nível (II), Expression of annoyance or disapproval, diz respeito a referências vagas e indiretas por parte do queixoso em relação à ofensa, sem explicitar a ofensa ou o visado. O terceiro nível (III), Explicit complaint, diz respeito, como o próprio nome indica, à realização explícita da queixa enquanto FTA, não obstante não existir por parte do queixoso o desejo de sanções. Accusation and warning é o quarto nível (IV) e distingue-se do anterior pelo facto de o FTA implicar além da queixa uma potencial sanção. O último nível (V), Immediate threat, é realizado através de um FTA em que manifestamente o queixoso ataca o visado, recorrendo, por exemplo, a insultos.

Murphy \& Neu (I996) apresentam, no estudo que levaram a cabo com informantes norte-americanos, uma classificação de natureza semântica dos 
elementos que compõem a queixa, isto é, a sua estrutura interna: i) explanation of purpose, em que o queixoso explica o motivo da queixa ao visado; ii) complaints, momento em que o queixoso efetiva a queixa; iii) justification, em que o queixoso argumenta, justificando, a sua posição e iv) candidate solution, quando o queixoso apresenta uma forma de remediação.

\subsection{Estratégias linguísticas no ato ilocutório de queixa}

Como é que o queixoso se queixa, isto é, que mecanismos linguísticos escolhe para manifestar o seu desagrado é uma questão que não reúne consenso. Ao contrário de outros FTA, a queixa não tem marcadores de força ilocutória (MFI) claramente identificáveis, porque não existem mecanismos linguísticos explícitos como MFI de queixa (fórmulas ritualizadas, verbos performativos, etc), dada a natureza complexa e conflitiva do ato. Ainda que não seja provável inventariar consensualmente os MFIs que codificam a queixa, é possível descrever estratégias linguísticas usadas, nomeadamente reforçadores e atenuadores do FTA.

A este propósito, Trosborg (I995: 3I3) apresenta um conjunto de estratégias que permitem minimizar o impacto que o FTA tem no visado: (i) evitar a explicitação do visado, considerando-o indiretamente culpado pela ofensa através da focalização na ofensa e nas consequências que derivam desta e não no agente - 'Já não vamos ouvir o João a falar!'; (ii) usar atenuadores 'Se calhar ainda chegamos a tempo de ouvir o João!'; (iii) recorrer ao discurso argumentativo - 'Temos de ir mais rápido para conseguir ouvir o João.'; (iv) substituir a componente conflituosa do ato ilocutório por uma informativa ou diretiva (pedido) - 'Podes andar mais depressa, por favor!'.

Como estratégias para maximizar o impacto do FTA no visado, encontramos (i) estratégias linguísticas (modalizadores enfatizadores) ao serviço do ato ilocutório de queixa - 'Não há dúvida nenhuma que vamos chegar atrasados' e (ii) atos ilocutórios integrados no speech act set de queixa: ameaças ' $N a$ próxima vez, não venho contigo'; injúrias e insultos 'És sempre o mesmo! Nunca chegas a horas a nada!'.

\section{Metodologia}

A metodologia usada foi a análise de corpus. Recorremos ao Corpus Oral de Português L2 (COral-Co) do Centro de Estudos de Linguística Geral e Aplicada 
da Universidade de Coimbra que disponibiliza um conjunto de produções orais de aprendentes adultos de PLNM (aprendizagem em contexto formal e experiências de imersão / inserção a frequentar, no momento da recolha, cursos e unidades curriculares de Português Língua Estrangeira na Faculdade de Letras da Universidade de Coimbra). Os dados foram recolhidos mediante a aplicação de um inquérito constituído por várias tarefas com objetivos diferentes. Numa das tarefas, os alunos foram convidados a produzir uma série de atos ilocutórios a partir de estímulos em contextos formal e informal.

Ao nosso estudo interessa o ato ilocutório de censura. Foi instigado em informantes, com várias línguas maternas, dos níveis $\mathrm{A} 2$, $\mathrm{BI}$ e $\mathrm{B} 2^{7}$, nos contextos formal (F) e informal (I ${ }^{8}$. O estímulo para a situação em contexto formal (F) foi: Imagine que um dos seus professores prometeu escrever-lhe uma carta de recomendação. Quando a vai buscar, ela ainda não está escrita e a sua entrevista de emprego tem lugar daí a 30 minutos. O que é que lhe dizia / diria? Para o contexto informal (I) foi dado o seguinte estímulo: Imagine que o seu irmão estragou as suas calças preferidas. O que é que the dizia / diria? Os dois contextos permitem equacionar as variáveis (D) e (P) em PLNM.

Para a nossa análise, consideramos apenas informantes hispanofalantes em 3 níveis de proficiência linguística - A2, Bi e B2. II informantes no total, sendo que 4 são de nível A2, 3 de Bi e 4 de B2. O número de informantes não permite conclusões, mas possibilita o desenho de atuações futuras e permite especular quanto a tendências.

Por último, é importante referir que o corpus obtido surge da resposta a um estímulo e não se coaduna com uma situação de interação comunicativa real (estrutura dialógica queixa-resposta), sendo o foco exclusivamente no queixoso.

\footnotetext{
$7 \mathrm{O}$ corpus não contempla informantes de nível Ci.

8 Ainda que a variável focada neste estudo seja o nível de proficiência linguística numa amostra hispanofalante, não descuramos a informação sociolinguística disponível relativa aos informantes. Dos II informantes, 7 são do género feminino (2 no nível A2, 2 no nível BI e 3 no nível B2) e 4 do género masculino (2 no nível A2, I nos níveis $\mathrm{B}$ I e B2, respetivamente). Em relação à nacionalidade, estão representados 4 países: Estados Unidos da América, Venezuela, Espanha e México.
} 


\section{Análise de dados e discussão dos resultados}

A análise dos dados de acordo com a taxonomia de Olshtain \& Weinbach (I993) apresenta dados bastante uniformes em (F). A maioria dos informantes (3 A2, I Bi e 3 B2) opta por realizar uma queixa de tipo (III), ou seja, uma queixa explícita. A queixa de tipo (II) é realizada nos níveis $\mathrm{A} 2$ e $\mathrm{BI}^{9}$ (I informante em cada nível), enquanto que a queixa de tipo (III) é concretizada em todos os níveis ${ }^{\mathrm{IO}}$. Salientamos que esta é a escolha da totalidade dos informantes de nível B2 que produz a queixa e que nenhum dos informantes deste nível realiza a queixa com elevado grau de indireção, optando sempre pela explicitação ou da ofensa ou do visado. É bastante interessante notar que I informante de nível B2 opta por não realizar o FTA ${ }^{\text {II }}$ apesar de essa opção não ter sido transmitida nas instruções ${ }^{\mathrm{I} 2}$, ao passo que um falante de nível BI opta por realizar uma queixa de tipo (IV), em que realiza de forma inequívoca o FTA, questionando o professor em relação à ofensa ${ }^{13}$.

Em relação à situação em contexto informal (I), o panorama é mais heterogéneo e demonstra maior grau de ameaça da face - tipos (III), (IV) e (V). Não há registo de preferência por queixas com reduzido grau de indireção - tipos (I) e (II) -, mas constatamos um maior leque de opções.

Atentando nos dados em função dos níveis de proficiência linguística, observamos que, em contexto formal, se regista uma preferência notória pela queixa tipo (III), não havendo indicação de que o nível de proficiência condicione o tipo de queixa realizado. As variáveis (D) e (P) favorecerão um tipo de queixa mais neutro do ponto de vista da ameaça da face, fazendo uso de estratégias de cortesia positiva e negativa para suavizar o impacto do FTA no visado.

Beltrán Palanques (2016: 137) refere que

the study conducted by Olshtain and Weinbach (1987) showed for example that there was a tendency to cluster around the centre of their classification

\footnotetext{
9 Informante 033_A2_T2_3_f; informante 042_BI_T2_3_f.

Io Informante 039_A2_T2_3_f; informante 048_A2_T2_3_f; informante 049_A2_T2_3_f; informante o3I_BI_T2_3_f; informante oI8_B2_T2_3_f; informante oI9_B2_T2_3_f; informante $027 \_\mathrm{B} 2 \_\mathrm{T} 2$-3_f.

II Informante O26_B2_T2_3_f. Não realizar o FTA é uma possibilidade prevista por Brown \& Levinson (I999: 316).

${ }^{12} \mathrm{O}$ facto de um aprendente optar por não realizar o FTA permite-nos perceber que também as características individuais dos falantes afetam a produção de FTAs e devem por isso ser tidas em consideração.

I3 Informante oo6_BI_T2_3_f.
} 
of complaints, avoiding the two extremes of the scale, and in the study carried out in I993, data revealed that similar moves were identified in some of the situations, but different in others.

A situação encontrada na totalidade do corpus analisado é semelhante aos resultados em Olshtain \& Weinback (1987) porque, em contexto formal, há uma tendência para a uniformização do tipo de respostas ao passo que, em contexto informal, a seguir descrito, identificamos uma tendência para a heterogeneidade.

No que se refere aos dados em contexto informal, registamos, no nível A2, I queixa tipo (III $)^{14}$, 2 queixas tipo (IV) ${ }^{15}$ e I queixa tipo $(\mathrm{V})^{16}$. No nível BI, identificamos 2 queixas tipo (III ${ }^{17}$ e I queixa tipo (IV) ${ }^{18}$. Já no nível B2, 2 queixas tipo (III) ${ }^{19}$ e 2 tipo $(\mathrm{V})^{20}$.

A partir da apreciação transversal (por níveis de proficiência linguística) dos dados em contexto informal é possível tecer algumas considerações. O maior grau de intimidade e a comunicação entre pares (sem hierarquias) favorece a realização de FTAs mais diretos e menos corteses bem como uma maior diversidade no que concerne o tipo de queixa realizado. Existe oscilação entre a preferência pela queixa de tipo (III) - que poderemos considerar a mais neutra - e as queixas de tipo (IV) e (V), registando-se, no entanto, uma tendência (seis informantes) para as que têm menor grau de indireção e, portanto, mais diretas e menos corteses. O nível de proficiência não condicionará a realização de queixas tipo $(\mathrm{V})$, uma vez que há um registo no nível A2.

Do ponto de vista da estruturação interna, as realizações analisadas em contexto formal não seguem taxativamente o modelo de estrutura interna proposto em Murphy \& Neu (I996).

A estrutura semântica é uniforme em relação à omissão da primeira componente-explanation of purpose. ${ }^{2 \mathrm{I}}$ Praticamente todas as queixas iniciam com

\footnotetext{
I4 Informante 048_A2_T2_3_i.

I5 Informante 033_A2_T2_3_i; informante 039_A2_T2_3_i.

${ }^{16}$ Informante 049_A2_T2_3_i.

${ }^{17}$ Informante 03I_BI_T2_3_i; informante 042_BI_T2_3_i.

${ }^{18}$ Informante 006_BI_T2_3_i.

I9 Informante oI8_B2_T2_3_i; informante oI9_B2_T2_3_i.

${ }^{20}$ Informante 026_B2_T2_3_i; informante 027_B2_T2_3_i.

${ }^{21}$ Esta evidência poderá dever-se ao facto de a queixa analisada ser resposta a um estímulo que não prevê a interação comunicacional mas apenas a manifestação do descontentamento por parte do queixoso.
} 
a componente complaints ${ }^{22}$, havendo depois oscilação entre as que apresentam um discurso argumentativo, seguido de proposta de remediação ou o contrário. A queixa 027_B2_T2_3_f é constituída apenas pela componente complaints.

Destacamos ainda duas realizações que não registam a componente candidate solution. A queixa 049_A2_T2_3_f ${ }^{23}$ assemelha-se mais a um lamento; o queixoso não parece contemplar a possibilidade de sugerir uma forma de remediação e a manifestação de desagrado é altamente modalizada, sem referência explícita à ofensa ou ao visado. Já na queixa oo6_BI_T2_3_f existe uma excessiva focalização no visado enquanto agente responsável pela ação e, por esse motivo, talvez possamos considerar que se trata de uma crítica e não de queixa ${ }^{24}$. Face a quanto antecede, estas duas realizações do ato ilocutório de queixa corresponderão a realizações desajustadas do ponto de vista pragmático, ou seja, constituem falhas sociopragmáticas 25 .

Em contexto informal, encontramos uma estrutura semântica da queixa bastante diferente. Das II realizações analisadas, 7 apresentam unicamente a componente complaints ao passo que a realização 039_A2_T2_3_i contempla as componentes complaints e candidate solution, e a 049_A2_T2_3_i as componentes complaints e justification.

Apesar de a totalidade evidenciar ausência de uma estrutura interna nos termos avançados por Murphy \& Neu (1996), é de assinalar as realizações

\footnotetext{
${ }^{22}$ Exceto a queixa do informante com o código oI9_B2_T2_3_f, em que a primeira componente é a candidate solution.

${ }^{23}$ Acreditamos ser interessante recuperar a distinção entre queixa direta e indireta para assinalar que a queixa indireta e o lamento podem coincindir. Ou por outras palavras, registar que podemos encontrar uma diferença equivalente entre queixa direta/queixa indireta e queixa direta/lamento. A queixa direta pode implicar uma tentativa de remediação do estado de coisas (ofensa), enquanto que a queixa indireta/ lamento dará conta unicamente do estado psicológico do falante em relação ao estado de coisas.

${ }^{24}$ Murphy \& Neu (1996: 205) apontam alguns elementos diferenciadores dos dois atos ilocutórios: "The complaint speech act set (...) exhibits features such as I) acceptance of partial responsibility, 2) depersonalization of the problem, 3) use of questions, 4) use of mitigators, and 5) use of the pronoun 'we'. [...] The speech act set of criticism is characterized in this instance by I) abdication of responsibility, 2) personalization of the problem, and 3) use of second person + modal 'should'".

${ }^{25} \mathrm{O}$ conceito pragmatic failure foi cunhado por Thomas (I983: 9I) e corresponde à "inability to understand 'what is meant by what is said'". Thomas (1983) distingue entre falha pragmalinguística e falha sociopragmática. A primeira diz respeito a questões essencialmente gramaticais, como é o caso, por exemplo, dos desvios na seleção do tempo e/ou modo verbais, enquanto que a falha sociopragmática está diretamente relacionada com convenções socioculturais associadas, por sua vez, à codificação linguística.
} 
033_A2_T2_3_i e oo6_BI_T2_3_i por não exibirem a componente complaints. Este facto reforça a dificuldade em encontrar MFIs característicos do ato de queixa. Na esmagadora maioria das realizações a força ilocutória do ato de queixa advirá da presença da complaints, independentemente da forma linguística que possa assumir ${ }^{26}$, mas não é a sua existência que garante a realização da queixa.

Por conseguinte, a componente semântica complaints pode (i) surgir isolada, carregando toda a força ilocutória de queixa (enquanto head-act), (ii) estar acompanhada por uma ou várias componentes, não obedecendo, nesse caso, a uma ordem sequencial, podendo ocorrer no speech act set em diferentes momentos, ou (iii) simplesmente estar ausente.

Realçar ainda que todas as realizações em contexto informal estão ajustadas do ponto de vista pragmático, isto é, há uma clara adequação das escolhas linguísticas à intenção comunicativa do queixoso.

Cabe destacar desta análise semântica que o contexto informal é muito mais flexível quanto à formulação da queixa que o contexto formal.

No seguimento dos enquadramentos taxonómicos, destacamos algumas evidências quanto às escolhas linguísticas dos informantes.

Retomando a situação em contexto formal (F), encontramos como principais estratégias linguísticas, tal como previsto por Trosborg (I995), o atenuador "por favor", as estruturas modalizadoras epistémicas, o recurso ao tempo verbal condicional / imperfeito de cortesia e a opção pela frase de tipo interrogativo como estratégia diretiva para a tentativa de remediação.

Apontamos as realizações 039_A2_T2_3_f e 048_A2_T2_3_f pelo facto de congregarem no mesmo speech act set 4 e 3 estratégias, respetivamente ${ }^{27}$. Salientamos a realização oo6_BI_T2_3_f pelo facto de apresentar oscilação entre a utilização do pronome pessoal 'tu' e 'você' num registo já por si pouco cortês e de cariz inquisitório. Esta evidência pode decorrer de um processo de transferência negativa da LI, bem como do não domínio das convenções socioculturais.

\footnotetext{
${ }^{26}$ Reparemos que, em contexto informal, a estrutura da queixa pode assumir contornos muito próximos da crítica, uma vez que, maioritariamente, há uma personalização da situação descrita, a escusa de responsabilidades e o uso da segunda pessoa do singular.

${ }^{27}$ A realização 039_A2_T2_3_f apresenta o uso de "por favor", o recurso à frase de tipo interrogativo para formular um pedido, uso do verbo modalizador 'poder' e estrutura modalizadora "penso que". Na realização 048_A2_T2_3_f constatamos o uso de "por favor", o recurso à frase de tipo interrogativo para formular um pedido e a estrutura modalizadora "é possível".
} 
Em contexto informal, as queixas estudadas são muito mais naturais e livres (não condicionadas por distância social ou relações de poder) e por esse motivo revelam diferenças, em relação ao contexto formal, na escolha dos mecanismos linguísticos que codificam a mensagem. As estratégias mais utilizadas são o recurso à frase de tipo interrogativo como forma de expressar o descontentamento e o uso de expressões insultuosas e ameaçadoras. É interessante notar que ao contrário do contexto formal, em que se registam opções linguísticas de modalidade epistémica ${ }^{28}$, em contexto informal, evidencia-se o recurso à modalidade deôntica na construção do ato diretivo ${ }^{29}$.

Deste modo, concluímos que as escolhas linguísticas são altamente condicionadas pelas variáveis $(\mathrm{D}),(\mathrm{P})$ e $(\mathrm{R})$ e poucas estão disponíveis para ambos os contextos - formal e informal - dado que no corpus analisado apenas registamos uma estratégia em ambos os contextos: recurso à frase de tipo interrogativo como forma de expressar a queixa. Salientamos, porém, que esta situação apenas se verifica porque em contexto formal esta escolha acontece no âmbito de uma realização de face-threat explícita e em que o speech act set pode inclusivamente ser considerado desrespeitoso para com o visado, tendo em conta que existe uma evidente relação de hierarquia académica ${ }^{30}$.

Em termos de estratégias de cortesia, é evidente o seu maior uso em contexto formal e a (quase) ausência no contexto informal. Este facto pode justificar-se pela consciência que os aprendentes têm das consequências negativas da realização deste ato ilocutório.

\section{Conclusões}

O estudo ora realizado nos termos propostos por Olshtain \& Weinbach (I993) e Murpy \& Neu (I996) constitui uma singela contribuição para o estudo dos atos ilocutórios em PLNM, nomeadamente do ato ilocutório de queixa na interlíngua.

A amostra aponta tendências na realização do ato de queixa, a saber: preferência pela realização da queixa de tipo (III); o contexto formal não é propício a queixas do tipo (IV) e (V); o contexto informal é propício a queixas do tipo (V); a estrutura semântica da queixa em contexto informal é muito mais livre que em contexto formal; as escolhas linguísticas são altamente condicionadas

\footnotetext{
${ }^{28}$ Informante 039_A2_T2_3_f.

${ }^{29}$ Informante 033_A2_T2_3_i.

${ }^{30}$ Informante oo6_BI_T2_3_f.
} 
pelas variáveis distância social (D) e poder (P), não havendo, normalmente, equivalência nas estruturas escolhidas para os dois contextos; as estratégias de cortesia são mais usadas em contexto formal, podendo até estar ausentes em contexto informal.

Face a quanto antecede, afigura-se-nos fundamental o estudo da queixa em PLM de modo a sistematizar este ato ilocutório em diferentes campos: estrutura interna, grau de ameaça da face, indireção e cortesia, identificação de potenciais MFIs e perspetiva do visado (resposta à queixa).

Conhecer o ato de discurso com valor ilocutório de queixa em PLM permitirá, posteriormente, fazer um estudo comparativo entre falantes nativos e não-nativos de diferentes línguas maternas e descrever as diferenças/semelhanças em termos de componentes, estratégias, indireção e cortesia.

\section{Bibliografia}

Beltrán Palanques, V. 20i6. Complaint sequences across proficiency levels (Tese de Doutoramento). Castellón de la Plana (Espanha): Universitat Jaume I. https:// www.tdx.cat/bitstream/handle/I0803/398842/2016_Tesis_BeltranPalanques. pdf? sequence $=\mathrm{I} \&$ is Allowed $=\mathrm{y}$

Blum-Kulka, S., \& Olshtain, E. I986. Too Many Words: Length of Utterance and Pragmatic Failure. Studies in Second Language Acquisition 8(02): I65-180.

Boxer, D. I993. Social distance speech behavior: The case of indirect complaints. Journal of Pragmatics I9: I03-I25.

Boxer, D. I993a. Complaints as Positive Strategies: What the Learner Needs to Know. TESOL Quarterly 27(2): 277-299.

Boxer, D. I996. Ethnographic interviewing as a research tool in speech act analysis: The case of complaints. Em Gass, S. M. \& Neu, J. Speech acts across Cultures: Challenges to Communication in a Second Language. Berlin: Mounton de Gruyter, 2I7-239.

Brown, P. \& Levinson, S. T. I999. Politeness: some Universals in Language Use. Em Jaworski, A. \& Coupland, N. The Discourse Reader. London/New York: Routledge, 3II-323.

Corpus Oral de Português L2 (COral-Co) http://teitok2.iltec.pt/coralco/ index.php?action $=$ descricao [Acesso oI/I2/20I8].

Geluykens, R. \& Kraft B. 2003. Sociocultural variation in native and interlanguage complaints. Em Jaszczolt, K. M. \& Turner, K. (eds.) Meaning Through Language Contrast. (2). Pragmatics \& Beyond, New Series. Amsterdam: John Benjamins Publishing Company, 251- 262. doi: 10.1075/pbns.I00.IGgel.

Ghaznavi, M. 20I7. The speech Act of Complaining: Definition and Characterization. https://semanticsarchive.net/Archive/DQIYTkzN/AhmadiComplaining.pdf [Acesso 26/12/2018]. 
Leech, G. N. I983. Principles of pragmatics. London: Longman.

Macêdo, C. M. M. I999. A reclamação e o pedido de desculpas: uma análise semântico-pragmática de cartas no contexto empresarial (Tese de doutoramento). São Paulo (Brasil): Pontifícia Universidade Católica de São Paulo. http://www.leffa.pro.br/ tela4/Textos/Textos/Teses / Celia_Macedo.pdf

Murphy, B. \& Neu, J. I996. My grade's too low: the speech act set of complaining. Em Gass, S. M. \& Neu, J. (eds.) Speech Acts across Cultures: Challenges to Communication in Second Language. Berlin: Mouton de Gruyter, I9I-2I6.

Olshtain, E. \& Weinbach, L. I993. Interlanguage features of the speech act of complaining. Em Kasper, G. \& Blum-Kulka, S. (eds.) Interlanguage Pragmatics. New York/Oxford: Oxford University Press, ı०8-I22.

Sabaté I Dalmau, M. 2009. The interlanguage of complaints by catalan learners of English. Em Gómez Morón, R.; Padilla Cruz, M.; Fernández Amaya, L. \& Hernández López, M. O. (eds.) Pragmatics Applied to Language Teaching and Learning. Newcastle: Cambridge Scholars Publishing, I4I-I64. https://www.academia. edu/63r6579/The_Interlanguage_of_Complaints_by_Catalan_Learners_of_ English

Searle, J. R. I976. A Classification of Illocutionary Acts. Language in Society 5(I): I-23. www.jstor.org/stable/4I66848

Thomas, J. I983. Cross-cultural Pragmatic Failure. Applied Linguistics 4(2): 9I-II2. https://rodas5.us.es/file/a26cdo6f-d8of-47b8-a5fo-fb23430aa5fc/I/thomas_ failure_wimba_SCORM.zip/files/thomas_pragmatic_failure.pdf

Toledo Azócar, S. 20I6. El Acto Queja: Estrategias Pragmáticas Empleadas por Hablantes Nativos del Español de Chile y Hablantes no Nativos, Aprendientes Del Español (Tese de Doutoramento). Valladolid (Espanha): Facultad de Filosofía y Letras de la Universidad de Valladolid. https://docplayer.es/98642393-Facultad-de-filosofia-y-letras-programa-de-doctorado-en-filologia-hispanica-tesis-doctoral. html

Trosborg, A. I995. Interlanguage Pragmatics: Requests, Complaints, and Apologies. Berlin: Mouton de Gruyter.

\section{Transcrição do corpus de análise}

http://teitok2.iltec.pt/coralco/index.php?action=descricao

[Acesso oI/I2/20I8]

\subsection{Contexto formal}

Informante 033_A2_T2_f

- Eu.... não sei.... como é que pôde fazer agora para... porque eu tenho uma entrevista de trabalio e, por favor, eu preciso de isso. 
Informante 039_A2_T2_f

É uma situação difícil, han? Bom, professor, eu pensei que você podia...havia fazer uma carta já para hoje, mas a minha entrevista são nos 30 minutos. Penso que, por favor, ainda pode escrivir a carta de recomendação?

Informante 048-9_A2_T2_3_f

Professor, não... não tenho tempo, preciso da carta. É(s) possível...huum... fazer muito rápida, por favor?

Informante 049-50_A2_T2_3_f

É uma pena porque... não faz mal... mas já não vou a precisar da carta porque eu precisava dela agora e já de(s)pois tenho que ir ao trabalho, à entrevista, e não posso esperar.

Informante 006_BI_T2_3_f

Ó professor, porque não tens feito o teu trabalho? Você falou, me disse que ia 'tar feito a recomendação.

Informante 03I_BI_T2_3_f

Professor, eu estou muito... eu sinto muito tirar do seu tempo, mas eu preciso mesmo de... da carta. Eu peço-lhe que a faça...faça a carta mesmo neste momento.

Informante 042_BI_T2_f

- Professor, eu tenho uma urgência pela entrevista que eu vou fazer para um trabalho que eu estou a procurar. Então, agradeceria que você podia fazer a carta.

Informante oI8_B2_T2_3_f

Eu diria muito respeitosamente: tenho a entrevista em 30 minutos e preciso da carta agora. Mas se não pode o professor a professora, então obrigado pela atenção mas tenho que ir embora.

Informante oI9_B2_T2_3_f

Poderia fazer a minha carta rapidinho? Era hoje e você não fez. 
Informante 026_B2_T2_3_f

A outra pessoa não cumple, mas não diria nada.

Informante 027_B2_T2_3_f

Professora, eu preciso da minha carta!

\subsection{Contexto Informal}

Informante 033_A2_T2_3_i

Tens que comprar-me umas novas.

Informante 039_A2_T2_3_i

Onde estão as minhas calças? Eu não tas emprestei? *talvez, pode ser* Então pois... o que fiz...eu não volto a emprestar as minhas calças.

Informante 048-9_A2_T2_3_i

Não sei porque porque é que fizeste isso.

Informante 049-50_A2_T2_3_i

Eu vou matar-te! Eram as minhas calças favoritas!

Informante oo6_BI_T2_3_i

Tem mais cuidado para a próxima.

Informante 03I_BI_T2_3_i

Eu gostava muito dessas calças, mas paciência, eu perdoo-te! Informante 042_BI_T2_3_i

Olha, tem mais cuidado com as minhas coisas. 
Informante oI8_B2_T2_3_i

*Me zangaria e diria* Porque fizeste issooo? *mas num tom muito zangado* Informante oI9_B2_T2_3_i

O que fizeste com minhas calças?

Informante 026_B2_T2_3_i

Estúpido, imbecil! Não podias fazer de outro modo?

Informante 027_B2_T2_3_i

Eu te mato 